
\title{
25 Resarch Square \\ Hypothetical Protein Predicted to Be Tumor Suppressor: A protein Functional Analysis
}

\section{Md. Abdul Kader}

Department of Biotechnology and Genetic Engineering, Mawlana Bhashani Science and Technology University, Santosh, Tangail-1902

\section{Md. Akash Ahmed}

Department of Biotechnology and Genetic Engineering, Mawlana Bhashani Science and Technology University, Santosh, Tangail-1902

\section{Md. Sharif Khan}

Department of Biotechnology and Genetic Engineering, Mawlana Bhashani Science and Technology University, Santosh, Tangail-1902

\section{Sheikh Abdullah Al Ashik}

Department of Biotechnology and Genetic Engineering, Mawlana Bhashani Science and Technology University, Santosh, Tangail-1902

\section{Md. Shariful Islam ( $\sim$ sharifbge@gmail.com )}

University of Kentucky

\section{Mohammad Uzzal Hossain}

Bioinformatics Division, National Institute of Biotechnology, Ganakbari, Ashulia, Savar, Dhaka-1349

\section{Research Article}

Keywords: Hypothetical protein, Functional annotation, Novel bacterium, VHL domain, Tumor suppressor

Posted Date: June 18th, 2021

DOl: https://doi.org/10.21203/rs.3.rs-602073/v1

License: (a) (i) This work is licensed under a Creative Commons Attribution 4.0 International License. Read Full License

Version of Record: A version of this preprint was published at Genomics \&amp; Informatics on March 31 st, 2022. See the published version at https://doi.org/10.5808/gi.21073. 


\section{Abstract}

\section{Background}

Litorilituus sediminis is a Gram-negative, aerobic, novel bacterium under the family of Colwelliaceae, has a stunning hypothetical protein containing domain called von Hippel-Lindau (pVHL) that has significant tumor suppressor activity. Therefore, this study was designed to elucidate the structure and function of the biologically important hypothetical protein EMK97_00595 (QBG34344.1) using several bioinformatics tools.

\section{Results}

The functional annotation exposed that the hypothetical protein is an extracellular secretory soluble signal peptide and containing the VHL (VHL beta) domain that has a significant role in tumor suppression. This domain is conserved throughout evolution, as its homologs are available in various types of the organism like mammals, insects, and nematode. The gene product of VHL has a critical regulatory activity in the ubiquitous oxygen-sensing pathway. This domain has a significant role to inhibit cell proliferation, angiogenesis progression, kidney cancer, breast cancer, and colon cancer.

\section{Conclusion}

At last, the current study depicts that the annotated hypothetical protein is linked with tumor suppressor activity which might be of great interest to future research in the higher organism.

\section{Background}

Bacteria possess tremendous compatibility that can be used to the necessity of human welfare and Litorilituus sediminis can be one of them. Litorilituus sediminis is a Gram-negative, aerobic, curved-rod shaped, non-spore-forming, catalase, and oxidase-positive bacterium with the polar or sub-polar flagellum. It was isolated from a sediment sample that was collected from the coastal region of Qingdao, China [1]. This organism grew optimally at $37^{\circ} \mathrm{C}, \mathrm{pH} 8-9$. This type of bacterium was novel among the other genera under the family of Colwelliaceae. The characteristics like phenotypic, chemotaxonomic, and well-confirmed phylogenetic evidence of Litorilitus belongs to the family Colwelliaceae was distinctive that implied as a novel genus. This novel bacterium has a prominent concentration of cellular constituents comparing with other genera and these are C16:0 and C16:1 $\omega 7 \mathrm{c}$ fatty acids, Phosphatidylethanolamine (PE), phosphatidylglycerol (PG), aminophospholipid (PN), and two amino lipids (AL1, AL2) as well as isoprenoid quinone 8 [1]. Along with bacterial cellular components, a profuse number of proteins exist where approximately $2 \%$ of the genes code for proteins as well as the remaining are non-coding or still functionally unknown [2].

The number of genes having unknown functions referred to as hypothetical proteins is present in each organism's genome [3] and these are a category of the protein whose existence is not confirmed by any 
experimental evidence but can be predicted to be expressed from an open reading frame (ORF) [4]. The hypothetical proteins can be classified as uncharacterized protein families (UPF) which are experimentally verified to exist but have not been identified or linked to a known gene, and the other type is the domain of unknown functions (DUF) [5] that is experimentally characterized proteins in the absences of known functional or structural domains [6][7]. Despite the lack of functional characterization, they play a significant role in understanding biochemical and physiological pathways like to explore new structures and functions [8], pharmacological targets and markers [9], and early detection and benefits for proteomic and genomic research [10]. With the advancement of Computational Biology, it has become easier to analyze hypothetical proteins using bioinformatics tools that provide various advantages like the determination of 3D structural conformation, identification of new domains and motifs, assessment of new cascades and pathways, phylogenetic profiling, and functional annotation [11].

However, due to novel genera under the family of Colwelliaceae, this study intended to characterize the protein EMK97_00595 [Litorilituus sediminis], a family of von Hippel-Lindau (VHL) that have an overwhelming function as a tumor suppressor in higher organisms. The main feature of VHL is that it is a critical regulator of the ubiquitous oxygen-sensing pathway and can act as a substrate recognition component of an E3 ubiquitin ligase complex [12], also promote the degradation of epidermal growth factor receptor, pro-angiogenesis factors, remodeling of the extracellular matrix, and helps in apoptosis resulting tumor suppression[13].

In the higher organism during cellular normoxia when oxygen is available, the cellular HIFa is hydroxylated by prolyl hydroxylase and works as a felicitous substrate for $\mathrm{pVHL}$ which is a constitutive active site of E3 ubiquitin ligase. The hydroxyproline of hydroxylated HIFa provides a binding signal for pVHL, which leads to efficient ubiquitylation and proteasomal degradation of HIFa protein. On the other hand, in hypoxia condition HIFa is not prolyl hydroxylated and may escape pVHL recognition, resulting in accumulation of HIFa and formation of a complex with HIF1 $\beta$, goes into the nucleus and activates a transcriptional program to cope with the short-term, long-term effects of oxygen deprivation, several signaling pathways as well as angiogenesis factor for leading cell proliferation or tumor [13][14]. So the function of the hypothetical protein that exists in the Litorilituus sediminis is considerable.

Therefore, this study manifests a reliable interpretation of this hypothetical protein EMK97_00595 (QBG34344.1) by adopting an integrated workflow that can be a potential research interest in the field of tumor suppression study.

\section{Methods}

Schematic representations of the overall experimental design were depicted in Figure 1.

\section{Sequence retrieval and similarity identification}

The hypothetical protein EMK97_00595 [Litorilituus sediminis] was chosen by exploring the NCBI database which can act as a significant research interest in numerous cancer research fields in the near 
future. The sequence of the hypothetical protein (GenBank Accession: QBG34344.1 and NCBI Reference Sequence: WP_130598461.1) that may contain a tumor suppressor domain was retrieved and collected as a FASTA format and submitted to several prediction servers for the in-silico characterization. Initially, a similarity search was performed using the NCBI BLASTp program [15] against the non-redundant and Swissprot database [16], for predicting the function of the hypothetical protein.

\section{Multiple sequence alignment and phylogeny analysis}

A multiple sequence alignment is a tool used to explore closely related genes or proteins to find the evolutionary relationships between genes and to identify shared patterns among functionally or structurally related genes. Sequence alignment was performed by the MUSCLE server of EBI [17], and an evolutionary relationship was accomplished by Jalview 2.11 software [18], between the hypothetical protein EMK97_00595 and the proteins that had structural similarity with the protein of interest.

\section{Analysis of physicochemical properties}

ProtParam [5] is a tool that computes various physical and chemical parameters of protein sequences. The physicochemical properties of the hypothetical protein were predicted using the ProtParam tool in the ExPASy server [19], which predicts all the relative properties including molecular weight, theoretical pl, amino acid composition, the total number of positive and negative residues, instability index, aliphatic index and grand average of hydropathicity (GRAVY) [20][21][22].

\section{Analysis of the secondary structure}

The servers that are utilized to predict protein secondary structure were SOPMA [23] and PSIPRED [24]. SOPMA is a general secondary structure prediction tool, on the other hand, PSIPRED is a server for comprehensive analysis of protein. The server SOPMA was initially employed to predict the secondary structure and then the result derived from the SOPMA server was validated by exploiting PSIPRED.

\section{D Structure Modeling and Quality Assessment}

HHpred server [25] that works based on the pairwise comparison profile of hidden Markov models, was used to build the 3-dimensional structure using the best scoring template. The confidence of the predicted structure was also visualized by SWISS-MODEL [26]. Several quality assessment tools of the SAVES and ProFunc [27] server were applied to estimate the reliability of the predicted 3D structure model of the hypothetical protein. The Ramachandran plot for the model was built using the PROCHECK program [28] to visualize the backbone dihedral angles of amino acid residues. The quality of the protein 3D structure was assessed with the help of the ERRAT server [29] and Varify 3D server was used to determine the compatibility of an atomic model (3D) with its amino acid sequence as well as comparing the results to standard structures [30][31].

\section{Active site determination}


Computed Atlas of Surface Topography (CASTp) is an online active site determination server [32] that calculates the location, delineation, and concave surface regions on 3D structures of proteins. CASTp predicted the active site of the selected hypothetical protein that showed the binding sites, amino acid binding regions with area and volume.

\section{Identification of protein subcellular localization and topology}

The subcellular location of the following protein was predicted by using the BUSCA web server [33]. BUSCA amalgamates different tools - DeepSig, TPpred3, PredGPI, BetAware, ENSEMBLE3.0, BaCelLo, MemLoci, and SChloro to predict protein features related to localization. The result was further checked by Cello [34], PsortB [35], Gneg-mPLoc [36], SOSUIGramN [37], and PSLpred [38]. Prediction of signal peptide was done by using PrediSi [39] and SignalP-5.0 Server [40]. The solubility of the hypothetical protein was evaluated by Protein-sol [41] and SOSUI [42] webserver. Protein transmembrane helices were assessed by HMMTOP [43], TMHMM [44] and, Sable [45] webserver. The topology of hypothetical protein was predicted by the ProFunc server [13].

\section{Prediction of protein domain, superfamily, family, coil, and folding pattern}

Domain/Superfamily/Family of the following hypothetical protein was analyzed by using the servers CDD from NCBI [46], Pfam [47], SMART [48], Interpro [49], SCOP [50][51], Supfam [52], Motif , ProFunc [27], Phyre [53], and CATH-Gene3D [54]. Among them, CDD, Pfam, SMART, Interpro, SCOP, Supfam, MotifFinder were employed to predict function from the sequence of the hypothetical protein, and ProFunc, Phyre 2, and CATH-Gene3D servers were used to predict the function from the 3-dimensional structure of the hypothetical protein. Only the lowest e-value was considered to determine protein classification, which indicates good similarity. The protein folding pattern was determined by using Phyre 2 and PFPFunDSeqE [55] servers where protein coil nature was determined by using PCoils [56] from the Bioinformatics toolkit server.

\section{Generation of Protein-protein interaction network}

As the proposed investigation seeking a tumor suppressor protein from microorganisms, STRING [57] has been used to summarize the network information of VHL tumor suppressor protein. Because of being a novel microorganism, there is no specific network is available. Here the VHL protein from humans has been used as a supposition model that might give an intellectual knowledge about VHL protein if it may apply to the human.

\section{Results}

\section{Identification of sequence homology}

The BLASTp result of the FASTA sequence shows the sequence homology with other identical proteins (Tables 1 and 2). Construction of phylogenetic tree using multiple sequence alignment generated from 
BLASTp result shows the evolutionary relationship of the selected hypothetical protein (WP_130598461.1) in Figure 2.

\section{Analysis of physicochemical properties}

The physicochemical properties of a protein can be characterized by an analysis of the analogous properties of the amino acids. The hypothetical protein is negatively charged as the theoretical pl: 4.22 and the total number of positively (Arg + Lys) and negatively charged residues (Asp + Glu) were found to be 10 and 27, respectively. The computed instability index (II) was 32.71 classifying the protein as a stable one. The aliphatic index was 77.37 which gives an indication of proteins' stability over a wide temperature range and all the other properties have been summarized in table 3 .

\section{Secondary structure analysis}

The secondary structure of a protein can be able to provide some worthy information about the function. The query hypothetical protein shows the percentages of alpha-helix, beta-turn, extended strand, and the random coil of protein $21.13 \%, 9.91 \%, 33.33 \%$, and $36.15 \%$, respectively from SOPMA. The results of the secondary structure were also cross-checked by the PRISPRED server which shows a summary of similar results. The representative secondary structure of the hypothetical protein (WP_130598461.1) has been shown in Figure 3.

\section{Assessment and validation of protein 3-dimensional structure}

PROCHECK program was used for the validation of predicted tertiary structure, where the distribution of $\varphi$ and $\psi$ angle in the model within the limits are shown (Table 4, Figure. 4). The model was presumed to be a good one according to the Ramachandran Plot Statistics, with $91.1 \%$ residues in the most favored regions. Finally, the structure validation server Verifiy3D and ERRAT was implicated to verify the established model of 3D structure for the target sequence. In the Verify3D graph, $93.75 \%$ of the residues have averaged a 3D-1D score $\geq$ of 0.2 which indicates that the environmental profile of the model is good and the overall quality factor predicted by the ERRAT server was 60.7143 indicates a quality model (Figure. 5). From ProFunc, the average G-factors of the hypothetical protein are calculated to be -0.20 , which indicates a usual protein model.

The active site of the selected hypothetical protein constituted by 11 amino acids of an area with 52.957 and a volume of 22.609. Chain $X$ of the hypothetical protein shows the amino acids involved in the active site $(F, V, Y, Y, T, L, E, V, T, Q, W)$, supplementary Figure 6 (A \& B).Active site calculation

\section{Assessment of protein subcellular localization and topology}

The subcellular localization of the hypothetical protein seems to be an extracellular secretory signal peptide. Protein-sol and SOSUI both predict the hypothetical protein as a soluble protein. HMMTOP, TMHMM predicted the protein as a non-transmembrane protein (Table 5). The predicted topology of the protein has shown here from $\mathrm{N}$ terminal to the $\mathrm{C}$ terminal (Figure 7). 


\section{Functional annotation of the hypothetical protein}

The initial protein domain was achieved from the Conserved domain database (CDD) of NCBI. The region of the domain, superfamily, and family classifications have been determined by the servers - CDD, Pfam, SMART, Interpro, SCOP, Supfam, MotifFinder, ProFunc, Phyre 2, and CATH-Gene3D. The domain, Superfamily, and Family were selected based on the lowest e-value of the following domain. The higher evalue has been filtered out from the selection procedure. The e-value 9.11e-05 of VHL beta domain from ProFunc, 2.71e-09 of VHL superfamily from SCOP, 8.1e-03 of VHL family from Supfam indicate extremely good protein alignment respectively. The overall alignment range of the VHL beta domain was 133-212, VHL superfamily and Family were $144-200$ respectively. Protein coil nature was determined by using PCoils from the Bioinformatics toolkit server. According to Phyre 2, the folding pattern of the following hypothetical protein is pre-albumin-like. On the other hand, PEF-FunSeqE is called the protein immunoglobulin-like. Both are secreted protein as well as soluble protein and hence provide a properly defined similarity indication of VHL protein (Table 6).

\section{Analysis of protein network}

The STRING interaction of VHL protein from Homo sapiens has been shown in Figure 8 as a model. VHL interacts with various proteins based on their combined score (table 7). The network has 11 nodes, 40 edges, average node degree 7.27 , local clustering coefficient 0.819 , expected number of edges 18 , and the p-value of protein-protein interaction enrichment 7.07e-06 indicates the network has significantly more interactions than expected.

\section{Discussion}

The sequence information as well as the structural information contributes to understanding the function of a hypothetical protein. This study aims to characterize a hypothetical protein, which showed strong homology with VHL superfamily, involved in tumor suppressor. Therefore, the amino acid sequence of the hypothetical protein EMK97_00595 [Litorilituus sediminis] was retrieved, and initially, the physicochemical properties were obtained by ExPASy's ProtParam tool and the prediction results are the deciding factors for the hydrophilicity, stability, and function of the protein [58]. The protein was considered as a stable one even in a wide temperature range as the instability index (II) and the aliphatic index were 32.71 and 77.37 , respectively. And the query protein seems to be hydrophilic as the GRAVY was -0.261 , supplementary table 3 .

Protein structure is closely associated with its function. The secondary structure, viz. helix, sheet, turn and therefore the coil of any protein has an excellent association with the structure, function, and interaction of the protein. The query hypothetical protein contains the percentages of alpha-helix, beta-turn, extended strand, and the random coil $21.13 \%, 9.91 \%, 33.33 \%$, and $36.15 \%$, respectively. Findings from SOPMA revealed that the protein has an abundance of coiled regions that contributes to higher stability and conservation of the protein structure [58]. Moreover, the protein features a reliable helices percentage in 
its structure, which may facilitate folding by providing more flexibility to the structure, thus protein interactions could be increased [59].

For the prediction of the protein 3D model, HHpred was employed, where the highest identical template was selected for getting an acceptable model. The query protein WP_012259469.1 showed the highest template identity of $25 \%$ with von Hippel-Lindau disease tumor suppressor; E3 ubiquitin ligase, transcription factor, hypoxic signaling, transcription; [Homo sapiens] with lowest E-value: 1.1e-11. Ramachandran plot analysis revealed that $91.1 \%$ of residues were located in the most favored regions. Moreover, residues in additional allowed regions and generously allowed regions were $7.1 \%$ and $0.0 \%$, respectively, which evaluated the quality of the model to be good and reliable as it is generally accepted that if $90 \%$ of residues are in the most favored regions, it is likely to be a reliable model [60], shown in Fig. 4(B). The model is compatible with its sequence as Verify 3D analysis implies that $93.75 \%$ of the residues had an average 3D-1D score of $\geq 0.2$. "Overall quality factor" was estimated by ERRAT, which is used to evaluate the amino acid environment for non-bonded atomic interactions. Higher scores indicate higher quality, and the query protein's quality factor was 60.7143 , which is greater than the generally accepted range $(>50)$ for a high-quality model [61]. The average G-factor of the query protein is -0.20 obtained from ProFunc analysis, which indicates a usual protein model.

Protein's active site was determined by CASTp, containing 11 amino acids ( $F, V, Y, Y, T, L, E, V, T, Q, W)$ of an area with 52.957 and a volume of 22.609, shown in Fig. 5. The subcellular localization obtained from CELLO, BUSCA, and other similar servers, seems to be an extracellular secretory signal peptide and nontransmembrane (Table 5). As the functions of secreted proteins are diverse, the query hypothetical protein may work like paracrine, autocrine, endocrine, or neuroendocrine depending on the target [62]. Solubility is the most important factor and an excellent index for protein functionality. Protein-sol and SOSUI both predict the hypothetical protein as a soluble one, so it may possess good dispersibility and lead to the formation of finely dispersed colloidal systems.

The superfamily, family, and domain information have been determined by a combinational sequence and structural informative approach based on the e-value of different sequence and structure analysis servers. These servers suggested the following hypothetical protein EMK97_00595 from the organism Litorilituus sediminis to be a VHL beta domain from the VHL superfamily. VHL tumor suppressor protein can play role in tumor suppression in multiple ways and the most common of them is targeting the hypoxia-inducible transcription factor (HIF) that mediated tumor suppression activity through polyubiquitylation and proteasomal degradation [63]. The major contribution of Von Hippel-Lindau tumor suppressor protein (pVHL) is to suppress clear-cell renal cell carcinoma in kidney cancer [63][64].

Litorilituus sediminis is a novel species and the investigated protein EMK97_00595 is also novel so there is no specific STRING derived protein-protein network is available for this organism. The protein-protein interaction network analysis shown here from Homo sapiens is just for a supposition model to evaluate how the protein interacted in humans. The protein-protein interaction of VHL-HIF1A (Hypoxia-inducible factor 1-alpha) with a combined score of 0.999 indicated a strong relationship between these two 
proteins. The interaction between VHL and HIF1A indicating the involvement of the same pathway to suppress tumor activity [12].

Overall, the combinational strategy of computing physicochemical properties, evaluating the secondary structure and tertiary structure information, and domain information analysis denoted the protein as Von Hippel-Lindau tumor suppressor protein that is associated with Von Hippel-Lindau disease.

\section{Conclusion}

Protein is the building block of life that serves both biological processes and molecular functions in living organisms. Hence, this study investigated the functional role of a hypothetical protein from a novel bacterium, (Litorilituus sediminis) that possesses a significant tumor suppression activity. The employment of highly recommended bioinformatics tools to analyze the combinational sequence and structural information revealed the underlying molecular function of the examined hypothetical protein. The current investigation suggested that the hypothetical protein may exhibit a VHL beta-domain that is similar to the human VHL beta-domain and is also a part of Von Hippel-Lindau tumor suppressor protein ( $\mathrm{VVHL}$ ). Therefore, this finding with the aid of bioinformatics tools can soften our viewpoint for further investigation and experimental validation of this hypothetical protein containing VHL beta domain, and the use of this hypothetical protein with the aid of modern biotechnology might be utilized to suppress tumor progression in higher organisms such as human as an alternative to human defective or mutated VHL protein in the near future.

\section{Abbreviations}

VHL: von Hippel- Lindau

PE: Phosphatidylethanolamine

PG: phosphatidylglycerol

PN: aminophospholipid

AL: amino lipids

ORF: open reading frame

DUF: domain of unknown functions

CDD: Conserved Domain Database

GRAVY: grand average of hydropathicity

CASTp: Computed Atlas of Surface Topography 
AKT: RAC-alpha serine/threonine-protein kinase

CUL2: Cullin-2

EPAS: Endothelial PAS domain-containing protein

HIF1A: Hypoxia-inducible factor 1-alpha

PPP2CA: Serine/threonine-protein phosphatase 2A catalytic subunit alpha isoform

\section{Declarations}

\section{Author Contribution}

Conceptualization and Methodology was performed by MAK, MSK, SAA, MSI, MUH; Formal analysis and Data curation was performed by MUH, and MAK; Writing-original draft prepared by MUH, SAA, MSK and MSI; Writing-review and editing performed by MUH, MAK and MSI; Supervised by MUH, MSI. All authors have read and agreed to submit the final version of the manuscript.

\section{Ethics approval and consent to participate}

Not applicable

\section{Consent for publication}

Not applicable

\section{Availability of data sets}

All data generated and analyzed during this study are included in this article.

\section{References}

1. Wang Y, Zhao R, Ji S, Li Z, Yu T, et al. Litorilituus sediminis gen. nov. sp. nov., isolated from coastal sediment of an amphioxus breeding zone in Qingdao, China. Antonie van Leeuwenhoek, Int J Gen Mol Microbio/ 2013; 104:423-430.

2. Uhlen M, Oksvold P, Fagerberg L, Lundberg E, Jonasson $\mathrm{K}$, et al. Towards a knowledge-based Human Protein Atlas. Nat Biotechnol 2010; 28:1248-1250.

3. Naveed M, Tehreem S, Usman M, Chaudhry Z, Abbas G. Structural and functional annotation of hypothetical proteins of human adenovirus: prioritizing the novel drug targets. BMC Res Notes 2017; 10:706.

4. Bashir Z, Rizwan M, Mushtaq K, Munir A, Ali I. In Silico Structural and Functional Prediction of Phaseolus vulgaris Hypothetical Protein PHA VU_004G136400g. J Proteomics Bioinform 2017; 10:207-211. 
5. Jaroszewski L, Li Z, Krishna SS, Bakolitsa C, Wooley J, et al. Exploration of uncharted regions of the protein universe. PLoS Bio/ 2009; 7. doi:10.1371/journal.pbio.1000205

6. Bharat Siva Varma P, Adimulam YB, Kodukula S. In silico functional annotation of a hypothetical protein from Staphylococcus aureus. J Infect Public Health 2015; 8:526-532.

7. Mudgal R, Sandhya S, Chandra N, Srinivasan N. De-DUFing the DUFs: Deciphering distant evolutionary relationships of Domains of Unknown Function using sensitive homology detection methods. Biol Direct 2015; 10:1-23.

8. Nimrod G, Schushan M, Steinberg DM, Ben-Tal N. Detection of Functionally Important Regions in "Hypothetical Proteins" of Known Structure. Structure 2008; 16:1755-1763.

9. Shahbaaz M, Hassan MI, Ahmad F. Functional annotation of conserved hypothetical proteins from Haemophilus influenzae Rd KW20. PLoS One 2013; 8. doi:10.1371/journal.pone.0084263

10. Mohan R. Computational structural and functional analysis of hypothetical proteins of Staphylococcus aureus. Bioinformation 2012; 8:722-728.

11. Mills $\mathrm{CL}$, Beuning PJ, Ondrechen MJ. Biochemical functional predictions for protein structures of unknown or uncertain function. Comput Struct Biotechnol J 2015; 13:182-191.

12. Haase VH. The VHL/HIF oxygen-sensing pathway and its relevance to kidney disease. Kidney Int 2006; 69:1302-1307.

13. Zhang $\mathrm{Q}$, Yang $\mathrm{H}$. The roles of VHL-dependent ubiquitination in signaling and cancer. Front Oncol $2012 ; 2: 1-7$.

14. Blankenship C, Naglich JG, Whaley JM, Seizinger B, Kley N. Alternate choice of initiation codon produces a biologically active product of the von Hippel Lindau gene with tumor suppressor activity. Oncogene 1999; 18:1529-1535.

15. Johnson M, Zaretskaya I, Raytselis Y, Merezhuk Y, McGinnis S, et al. NCBI BLAST: a better web interface. Nucleic Acids Res 2008; 36:5-9.

16. Boeckmann B, Bairoch A, Apweiler R, Blatter MC, Estreicher A, et al. The SWISS-PROT protein knowledgebase and its supplement TrEMBL in 2003. Nucleic Acids Res 2003; 31:365-370.

17. Madeira F, Park YM, Lee J, Buso N, Gur T, et al. The EMBL-EBI search and sequence analysis tools APIs in 2019. Nucleic Acids Res 2019; 47:W636-W641.

18. Waterhouse AM, Procter JB, Martin DMA, Clamp M, Barton GJ. Jalview Version 2-A multiple sequence alignment editor and analysis workbench. Bioinformatics 2009; 25:1189-1191.

19. Gasteiger E, Hoogland C, Gattiker A, Duvaud S, Wilkins MR, et al. The Proteomics Protocols Handbook. Proteomics Protoc Handb 2005; :571-608.

20. Atsushi I. Thermostability and aliphatic index of globular proteins. J Biochem 1980; 88:1895-1898.

21. Kyte J, Doolittle RF. A simple method for displaying the hydropathic character of a protein. $\mathrm{J} \mathrm{Mol} \mathrm{Biol}$ 1982; 157:105-132.

22. Guruprasad K, Reddy BVB, Pandit MW. Correlation between stability of a protein and its dipeptide composition: A novel approach for predicting in vivo stability of a protein from its primary sequence. 
Protein Eng Des Sel 1990; 4:155-161.

23. Geourjon C, Deléage G. Sopma: Significant improvements in protein secondary structure prediction by consensus prediction from multiple alignments. Bioinformatics 1995; 11:681-684.

24. McGuffin LJ, Bryson K, Jones DT. The PSIPRED protein structure prediction server. Bioinformatics 2000; 16:404-405.

25. Zimmermann L, Stephens A, Nam SZ, Rau D, Kübler J, et al. A Completely Reimplemented MPI Bioinformatics Toolkit with a New HHpred Server at its Core. J Mol Biol 2018; 430:2237-2243.

26. Schwede T, Kopp J, Guex N, Peitsch MC. SWISS-MODEL: An automated protein homology-modeling server. Nucleic Acids Res 2003; 31:3381-3385.

27. Laskowski RA, Watson JD, Thornton JM. ProFunc: A server for predicting protein function from 3D structure. Nucleic Acids Res 2005; 33:89-93.

28. Laskowski RA, MacArthur MW, Moss DS, Thornton JM. PROCHECK: a program to check the stereochemical quality of protein structures. J App/ Crystallogr 1993; 26:283-291.

29. Colovos C, Yeates TO. Verification of protein structures: Patterns of nonbonded atomic interactions. Protein Sci 1993; 2:1511-1519.

30. Kihara D, Chen H, Yang Y. Quality Assessment of Protein Structure Models. Curr Protein Pept Sci 2009; 10:216-228.

31. Luthy R, Bowei J, Einsenberg D. Verify3D: Assessment of protein models with three-dimensional profiles. Methods Enzymol 1997; 277:396-404.

32. Tian W, Chen C, Lei X, Zhao J, Liang J. CASTp 3.0: Computed atlas of surface topography of proteins. Nucleic Acids Res 2018; 46:W363-W367.

33. Savojardo C, Martelli PL, Fariselli P, Profiti G, Casadio R. BUSCA: An integrative web server to predict subcellular localization of proteins. Nucleic Acids Res 2018; 46:W459-W466.

34. Yu C-S, Lin C-J, Hwang J-K. Predicting subcellular localization of proteins for Gram-negative bacteria by support vector machines based on n -peptide compositions . Protein Sci 2004; 13:1402-1406.

35. Yu NY, Wagner JR, Laird MR, Melli G, Rey S, et al. PSORTb 3.0: Improved protein subcellular localization prediction with refined localization subcategories and predictive capabilities for all prokaryotes. Bioinformatics 2010; 26:1608-1615.

36. Shen H Bin, Chou KC. Gneg-mPLoc: A top-down strategy to enhance the quality of predicting subcellular localization of Gram-negative bacterial proteins. J Theor Biol 2010; 264:326-333.

37. Imai K, Asakawa N, Tsuji T, Akazawa F, Ino A, et al. SOSUI-GramN: high performance prediction for sub-cellular localization of proteins in Gram-negative bacteria. Bioinformation 2008; 2:417-421.

38. Bhasin M, Garg A, Raghava GPS. PSLpred: Prediction of subcellular localization of bacterial proteins. Bioinformatics 2005; 21:2522-2524.

39. Hiller K, Grote A, Scheer M, Münch R, Jahn D. PrediSi: Prediction of signal peptides and their cleavage positions. Nucleic Acids Res 2004; 32:375-379. 
40. Almagro Armenteros JJ, Tsirigos KD, Sønderby CK, Petersen TN, Winther O, et al. SignalP 5.0 improves signal peptide predictions using deep neural networks. Nat Biotechno/ 2019; 37:420-423.

41. Hebditch M, Carballo-Amador MA, Charonis S, Curtis R, Warwicker J. Protein-Sol: A web tool for predicting protein solubility from sequence. Bioinformatics 2017; 33:3098-3100.

42. Mitaku S, Hirokawa T. Physicochemical factors for discriminating between soluble and membrane proteins: Hydrophobicity of helical segments and protein length. Protein Eng 1999; 12:953-957.

43. Tusnády GE, Simon I. The HMMTOP transmembrane topology prediction server. Bioinformatics $2001 ; 17: 849-850$.

44. Möller S, Croning MDR, Apweiler R. Evaluation of methods for the prediction of membrane spanning regions. Bioinformatics 2001; 17:646-653.

45. Wagner M, Adamczak R, Porollo A, Meller J. Linear regression models for solvent accessibility prediction in proteins. J Comput Biol 2005; 12:355-369.

46. Lu S, Wang J, Chitsaz F, Derbyshire MK, Geer RC, et al. CDD/SPARCLE: The conserved domain database in 2020. Nucleic Acids Res 2020; 48:D265-D268.

47. El-Gebali S, Mistry J, Bateman A, Eddy SR, Luciani A, et al. The Pfam protein families database in 2019. Nucleic Acids Res 2019; 47:D427-D432.

48. Letunic I, Khedkar S, Bork P. SMART: recent updates, new developments and status in 2020. Nucleic Acids Res 2021; 49:D458-D460.

49. Blum M, Chang H-Y, Chuguransky S, Grego T, Kandasaamy S, et al. The InterPro protein families and domains database: 20 years on. Nucleic Acids Res 2021; 49:D344-D354.

50. Gough J, Karplus K, Hughey R, Chothia C. Assignment of homology to genome sequences using a library of hidden Markov models that represent all proteins of known structure. J Mol Biol 2001; 313:903-919.

51. Pandurangan AP, Stahlhacke J, Oates ME, Smithers B, Gough J. The SUPERFAMILY 2.0 database: A significant proteome update and a new webserver. Nucleic Acids Res 2019; 47:D490-D494.

52. Pandit SB, Bhadra R, Gowri VS, Balaji S, Anand B, et al. SUPFAM: A database of sequence superfamilies of protein domains. BMC Bioinformatics 2004; 5:1-5.

53. Kelley LA, Mezulis S, Yates CM, Wass MN, Sternberg MJ. Trabajo práctico $N^{0} 13$. Varianzas en función de variable independiente categórica. Nat Protoc 2016; 10:845-858.

54. Sillitoe I, Dawson N, Lewis TE, Das S, Lees JG, et al. CATH: Expanding the horizons of structurebased functional annotations for genome sequences. Nucleic Acids Res 2019; 47:D280-D284.

55. Shen H Bin, Chou KC. Predicting protein fold pattern with functional domain and sequential evolution information. J Theor Biol 2009; 256:441-446.

56. Gruber M, Söding J, Lupas AN. Comparative analysis of coiled-coil prediction methods. J Struct Biol 2006; 155:140-145.

57. Szklarczyk D, Gable AL, Lyon D, Junge A, Wyder S, et al. STRING v11: Protein-protein association networks with increased coverage, supporting functional discovery in genome-wide experimental 
datasets. Nucleic Acids Res 2019; 47:D607-D613.

58. Hasan A, Mazumder HH, Chowdhury AS, Datta A, Khan A. Molecular-docking study of malaria drug target enzyme transketolase in Plasmodium falciparum 3D7 portends the novel approach to its treatment. Source Code Biol Med 2015; :1-14.

59. Butt AM, Batool M, Tong Y. functional annotation of Mycoplasma genitalium hypothetical protein MG _ 237. 2011; 7 .

60. Hooda V, Gundala P, Chinthala P. Sequence analysis and homology modeling of peroxidase from Medicago sativa Abstract: Background: 2012; 8.

61. Messaoudi A, Belguith H, Hamida J Ben. Evolutionary Bioinformatics Three-Dimensional Structure of Arabidopsis thaliana Lipase Predicted by Homology Modeling Method. ; :99-105.

62. Farhan H, Rabouille C, Farhan H, Rabouille C. Signalling to and from the secretory pathway Signalling to and from the secretory pathway. Published Online First: 2011. doi:10.1242/jcs.086991

63. Article O. Treatment of Kidney Cancer. Published Online First: 2009. doi:10.1002/cncr.24232

64. Clark PE. The role of VHL in clear-cell renal cell carcinoma and its relation to targeted therapy. Kidney Int 2009; 76:939-945.

\section{Tables}

\section{Table 1: Similar proteins obtained from the non-redundant database.}

\begin{tabular}{|c|c|c|c|c|c|c|}
\hline Accession & Description & Scientific Name & $\begin{array}{l}\text { Total } \\
\text { Score }\end{array}$ & $\begin{array}{l}\text { Query } \\
\text { Cover }\end{array}$ & $\begin{array}{l}\text { E- } \\
\text { value }\end{array}$ & $\begin{array}{l}\% \\
\text { Identity }\end{array}$ \\
\hline WP_118961164.1 & $\begin{array}{l}\text { hypothetical protein } \\
\text { [Colwellia sp. RSH04] }\end{array}$ & $\begin{array}{l}\text { Colwellia sp. } \\
\text { RSHO4 }\end{array}$ & 349 & $100 \%$ & $\begin{array}{l}5.00 E- \\
120\end{array}$ & $74.18 \%$ \\
\hline WP_033081725.1 & $\begin{array}{l}\text { hypothetical protein } \\
\text { [Colwellia } \\
\text { psychrerythraea] }\end{array}$ & $\begin{array}{l}\text { Colwellia } \\
\text { psychrerythraea }\end{array}$ & 235 & $100 \%$ & $\begin{array}{l}4.00 \mathrm{E}- \\
75\end{array}$ & $51.17 \%$ \\
\hline WP_142932219.1 & $\begin{array}{l}\text { hypothetical protein } \\
\text { [Aliikangiella } s p . \\
\text { M105] }\end{array}$ & $\begin{array}{l}\text { Aliikangiella sp. } \\
\text { M105 }\end{array}$ & 108 & $94 \%$ & $\begin{array}{l}2.00 \mathrm{E}- \\
25\end{array}$ & $34.78 \%$ \\
\hline WP_155746905.1 & $\begin{array}{l}\text { hypothetical protein } \\
\text { [Scytonema sp. UIC } \\
\text { 10036] }\end{array}$ & $\begin{array}{l}\text { Scytonema sp. } \\
\text { UIC } 10036\end{array}$ & 61.2 & $45 \%$ & $\begin{array}{l}3.00 \mathrm{E}- \\
08\end{array}$ & $34.02 \%$ \\
\hline BAZ36602.1 & $\begin{array}{l}\text { hypothetical protein } \\
\text { NIES4101_25210 } \\
\text { [Calothrix sp. NIES- } \\
4101]\end{array}$ & $\begin{array}{l}\text { Calothrix sp. } \\
\text { NIES-4101 }\end{array}$ & 57.8 & $27 \%$ & $\begin{array}{l}5.00 E- \\
07\end{array}$ & $44.83 \%$ \\
\hline
\end{tabular}

Table 2: Similar proteins obtained from Swissprot database 


\begin{tabular}{|c|c|c|c|c|}
\hline Entry & Protein names & Identity & Score & $\begin{array}{l}\text { E- } \\
\text { value }\end{array}$ \\
\hline A0A396TZK2 & Uncharacterized protein (Colwellia sp. $\mathrm{RSHO4}$ & $74.2 \%$ & 894 & $\begin{array}{l}1.3 e- \\
120\end{array}$ \\
\hline A0A545UCJ6 & VHL domain-containing protein (Aliikangiella sp. M105) & $34.3 \%$ & 81 & $\begin{array}{l}8.3 e^{-} \\
28\end{array}$ \\
\hline A0A1Z4R2C0 & $\begin{array}{l}\text { VHL domain-containing protein (Calothrix sp. NIES- } \\
4101 \text { ) }\end{array}$ & $36.6 \%$ & 150 & $\begin{array}{l}1.5 e^{-} \\
9\end{array}$ \\
\hline A0A116H391 & $\begin{array}{l}\text { Por secretion system C-terminal sorting domain- } \\
\text { containing protein (Robiginitalea myxolifaciens) }\end{array}$ & $37.1 \%$ & 133 & $7 e-6$ \\
\hline A0A2S7JPT4 & $\begin{array}{l}\text { VHL domain-containing protein (Limnohabitans sp. TS- } \\
C S-82 \text { ) }\end{array}$ & $35.1 \%$ & 124 & $2 e-5$ \\
\hline
\end{tabular}

Table 3: Physicochemical properties of the hypothetical protein (WP_130598461.1)

\begin{tabular}{|ll|}
\hline Properties & Value \\
\hline Molecular weight & 23229.44 \\
\hline Theoretical pl & 4.22 \\
\hline The total number of negatively charged residues (Asp + Glu) & 27 \\
\hline The total number of positively charged residues (Arg + Lys) & 10 \\
\hline The instability index (II) is computed to be & 32.71 \\
\hline Formula & $\mathrm{C}_{1024} \mathrm{H}_{1552} \mathrm{~N}_{262} \mathrm{O}_{346} \mathrm{~S}_{5}$ \\
\hline The total number of atoms & 3189 \\
\hline Aliphatic index & 77.37 \\
\hline Grand average of hydropathicity (GRAVY) & -0.261 \\
\hline
\end{tabular}

Table 4: Ramachandran plot statistics of the predicted 3D model for the target protein EMK97_00595 (WP_130598461.1) 


\begin{tabular}{|lll|}
\hline Plot Statistics & $\begin{array}{l}\text { Number of amino acid } \\
\text { residues }\end{array}$ & $\begin{array}{l}\text { Percentage } \\
(\%)\end{array}$ \\
\hline Residues in the most favored regions [A, B, L] & 51 & $91.1 \%$ \\
\hline Residues in additional allowed regions [a, b, l, p] & 4 & $7.1 \%$ \\
\hline $\begin{array}{l}\text { Residues in generously allowed regions [ a, } \sim \mathrm{b}, \sim \text { l, } \\
\sim \mathrm{p}]\end{array}$ & 0 & $0.0 \%$ \\
\hline Residues in disallowed regions & 1 & $1.8 \%$ \\
\hline Number of non-glycine and non-proline residues & 56 & $100.0 \%$ \\
\hline Number of end-residues (excl. Gly and Pro) & 2 & \\
\hline Number of glycine residues (shown as triangles) & 4 & 2 \\
\hline Number of proline residues & 64 & \\
\hline Total number of residues & 2 & \\
\hline
\end{tabular}

Table 5: Assessment of subcellular localization

\begin{tabular}{|lll|}
\hline Prediction & Servers & Results \\
\hline Prediction of subcellular localization & Busca & Extracellular space, Signal peptide \\
\cline { 2 - 3 } & Cello & Extracellular \\
\cline { 2 - 3 } & PsortB & Unknown, Signal Peptide \\
\cline { 2 - 3 } & Cell-PLoc & Extracellular \\
\cline { 2 - 3 } & PSLpred & Extracellular protein \\
\cline { 2 - 3 } Signal Peptide prediction & SOSUlgramN & Outer membrane \\
\hline Prediction of protein solubility & Predisi & Secreted protein, Signal peptide \\
\cline { 2 - 3 } & SignalP-5.0 Server & Signal Peptide \\
\hline Prediction of Transmembrane helices & SOSUI & Soluble protein \\
\cline { 2 - 3 } & Protein-sol & Soluble protein \\
\cline { 2 - 3 } & HMMTOP & None \\
\cline { 2 - 3 } & SMHM & None \\
\cline { 2 - 3 } & Sable & No transmembrane domain \\
\cline { 2 - 3 } & &
\end{tabular}

Table 6: Function annotation of hypothetical protein through the analysis of protein domain/superfamily/Family 


\begin{tabular}{|c|c|c|c|}
\hline Servers & Domain/Superfamily/Family & $\begin{array}{l}\text { e-value/ } \\
\text { Confidence }\end{array}$ & $\begin{array}{l}\text { Region/ } \\
\text { Alignment }\end{array}$ \\
\hline \multicolumn{4}{|c|}{ Functional annotation from sequence } \\
\hline $\begin{array}{l}\text { Conserved Domain Database } \\
\text { (CDD) }\end{array}$ & Superfamily: $\mathrm{pVHL}$ & $6.22 \mathrm{e}-05$ & $146-197$ \\
\hline Pfam & $\begin{array}{l}\text { Family: VHL (VHL beta } \\
\text { domain) }\end{array}$ & $1.3 e-02$ & $144-200$ \\
\hline SMART & VHL & $1.2 \mathrm{e}-02$ & $133-205$ \\
\hline \multirow[t]{2}{*}{ Interpro } & VHL superfamily & - & 144-199 \\
\hline & VHL beta domain & - & $131-212$ \\
\hline \multirow[t]{2}{*}{ Superfamily 1.75 (SCOP) } & Superfamily: VHL & $2.71 \mathrm{e}-09$ & \multirow[t]{2}{*}{ 144-199 } \\
\hline & Family: VHL & 8.1e-03 & \\
\hline \multirow[t]{2}{*}{ Supfam } & Superfamily: VHL & $1.54 \mathrm{e}-09$ & 144-199 \\
\hline & Family: VHL & $8.1 \mathrm{e}-03$ & \\
\hline $\begin{array}{l}\text { Motif } \\
\text { (From Pfam) }\end{array}$ & VHL beta domain & $8.1 \mathrm{e}-03$ & $146-200$ \\
\hline \multicolumn{4}{|c|}{ Functional annotation from the 3D structure } \\
\hline ProFunc & VHL beta domain & $9.11 \mathrm{e}-05$ & $131-191$ \\
\hline Phyre 2 & $\begin{array}{l}\text { Superfamily: VHL } \\
\text { Family: VHL }\end{array}$ & $\begin{array}{l}99.8 \% \\
\text { (Confidence) }\end{array}$ & $135-212$ \\
\hline CATH-Gene3D (From Interpro) & VHL beta domain & - & $131-212$ \\
\hline
\end{tabular}

Table 7: Interacting proteins and their combined score from STRING 11.0 server 
AKT1 (RAC-alpha serine/threonine-protein kinase)

0.997

AKT2 (RAC-beta serine/threonine-protein kinase)

0.994

CUL2 (Cullin-2; Core component of multiple cullin-RING-based ECS E3 ubiquitinprotein ligase complexes)

EGLN1 (Egl nine homolog 1)

EPAS1 (Endothelial PAS domain-containing protein 1)

0.994

HIF1A (Hypoxia-inducible factor 1-alpha)

0.999

PPP2CA (Serine/threonine-protein phosphatase 2A catalytic subunit alpha isoform)

0.993

RBX1 (E3 ubiquitin-protein ligase RBX1)

0.982

TCEB1 (Elongin-C)

0.999

TCEB2 (Elongin-B)

\section{Figures}

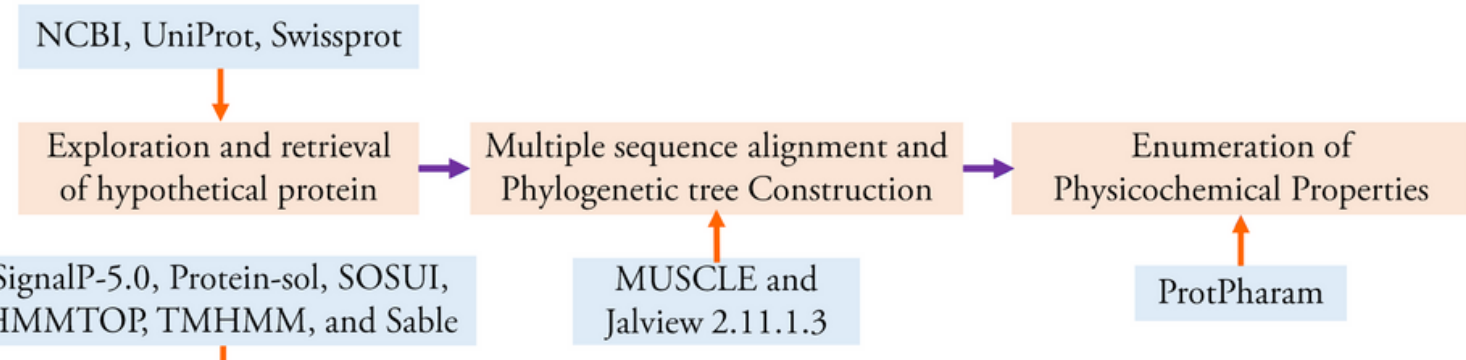

SignalP-5.0, Protein-sol, SOSUI,
HMMTOP, TMHMM, and Sable
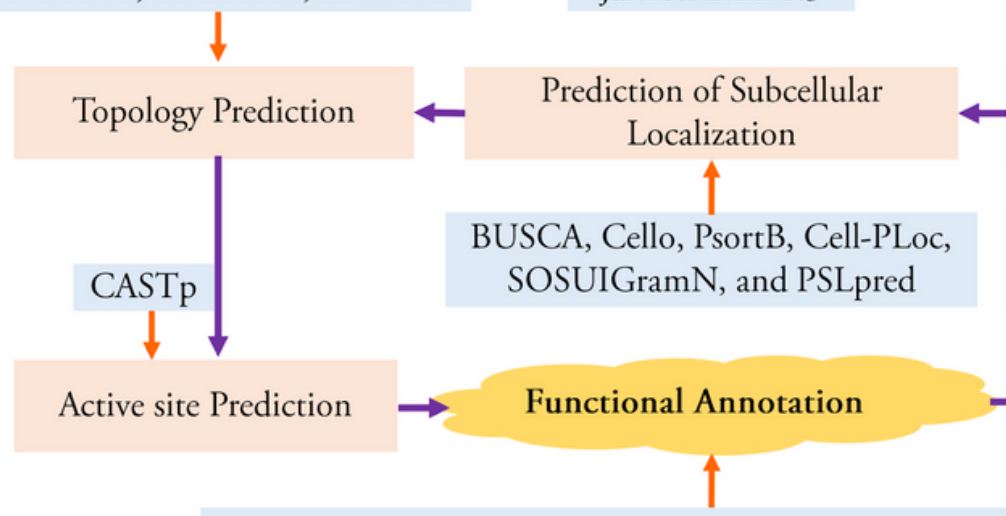

Assessment of Tertiary Structure

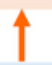

SAVES 6.0: ERRAT, Verify3D, and PROCHECK

SOPMA, and PSIPRED

Conserved Domain (CDD), SMART, Pfam, InterPro, Superfamily

1.75, Supfam, MotifFinder, ProFunc, Phyre 2, CATH-Gene3D, PFP-

FunDSeqE, and PCoils

\section{Figure 1}

A schematic representation of the overall experimental design. 


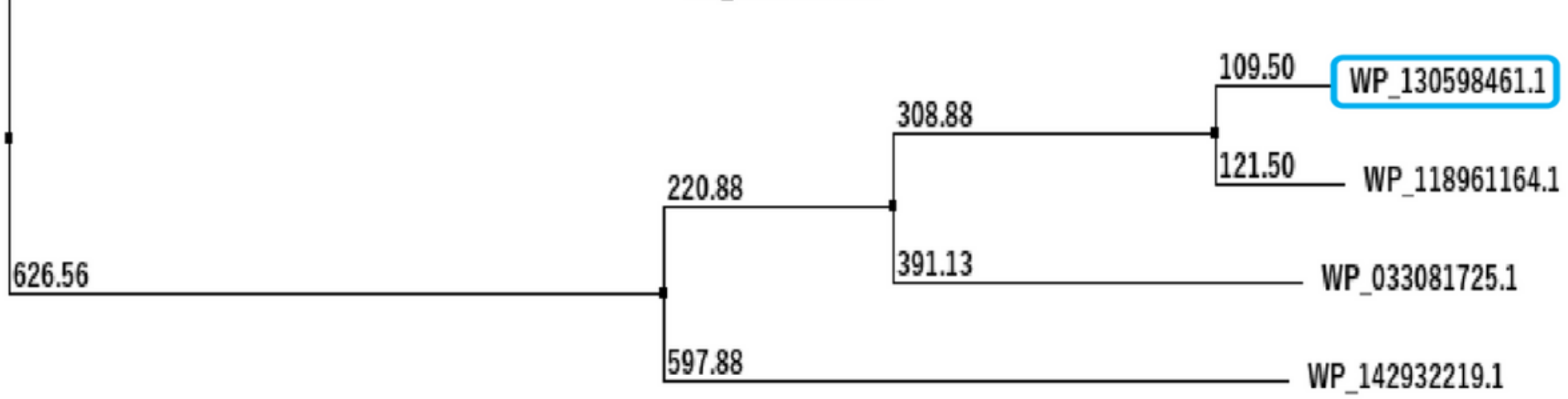

\section{Figure 2}

Evolutionary analysis of different VHL proteins with the target protein shown in the blue box (WP_130598461.1). 


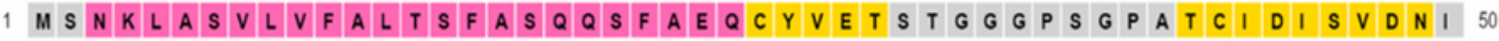

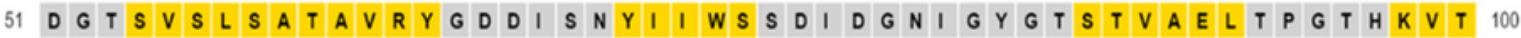

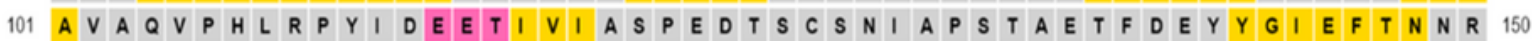

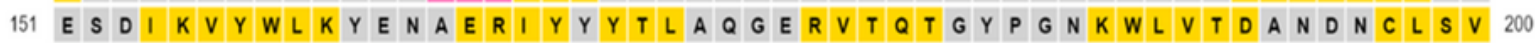
201 H

Strand
$\square$ Disordered, protein binding

Extracellular
20

Helix
Putative Domain Boundary
Re-entrant Helix

30

Coil

Membrane Interaction Cytoplas
213

50

\section{(A)}

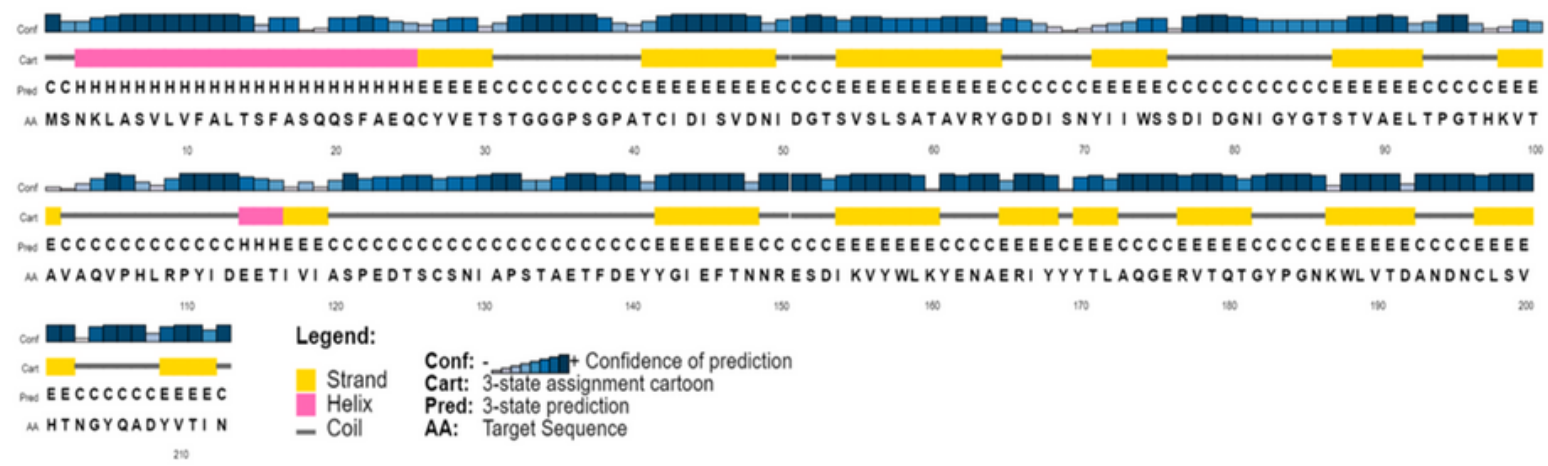

(B)
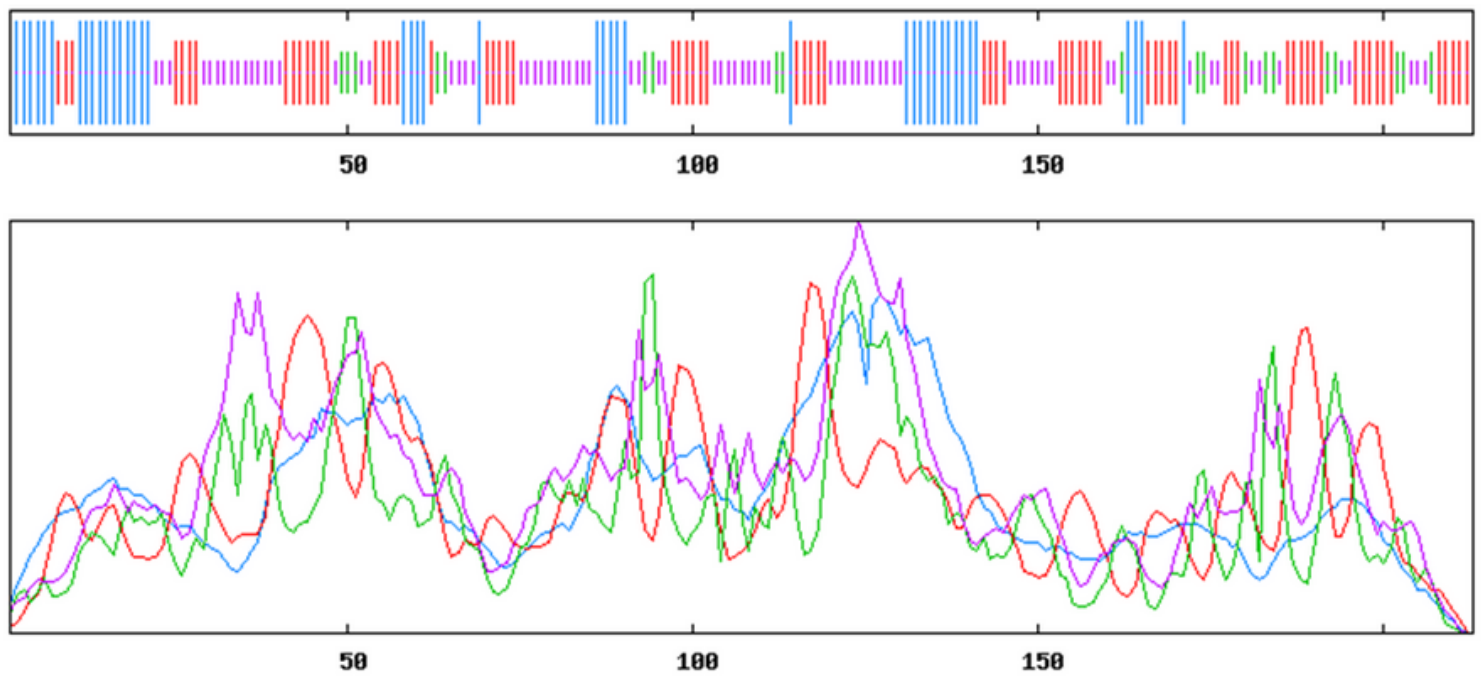

(C)

\section{Figure 3}

Model of secondary structure. (I) Secondary structure information from SOPMA server, and II (A) and (B) Sequential organization and graphical visualization of secondary structure from PSIPRED. 


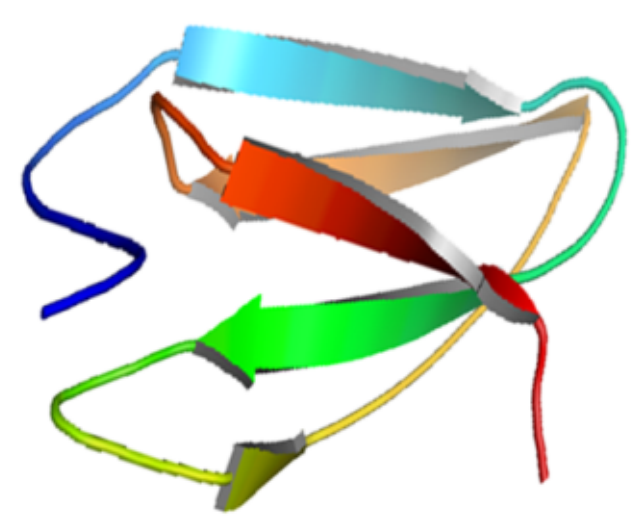

(A)

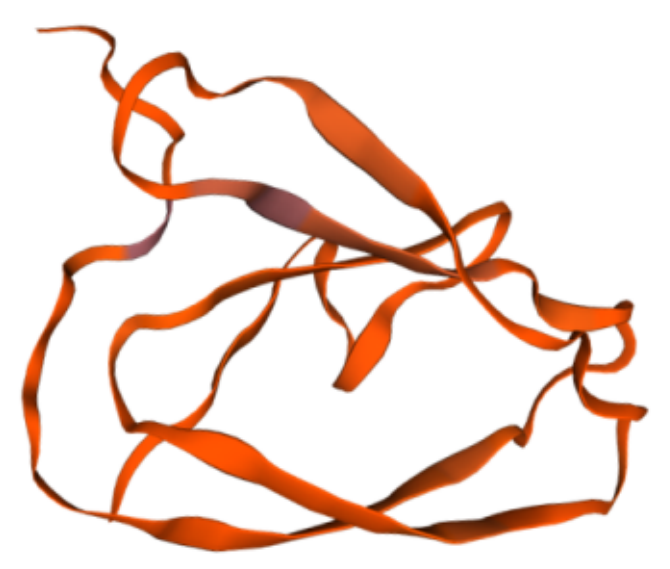

(B)

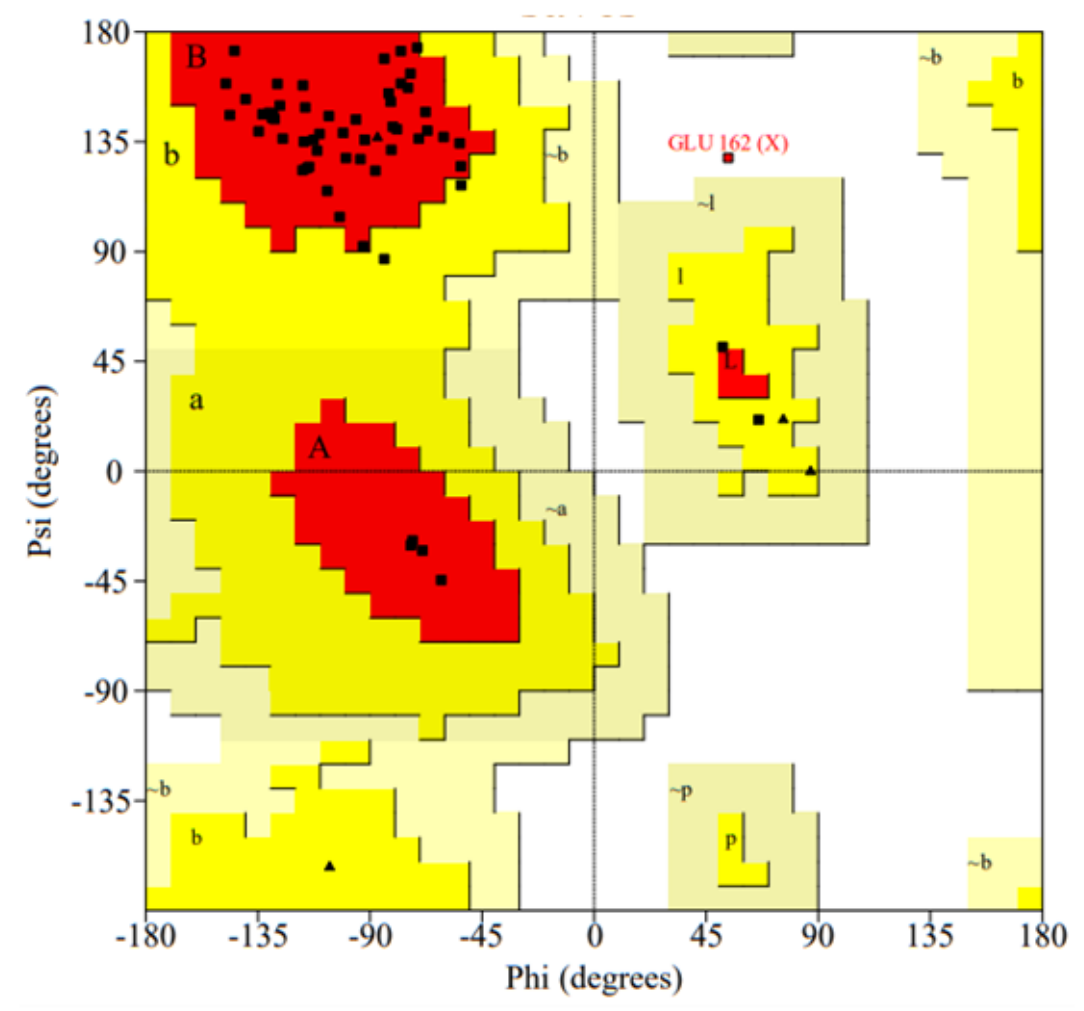

\section{Figure 4}

Graphical representation and assessment of protein 3D structure. (A) Predicted 3-dimensional structure from SAVES server (Pymol view), (B) from SWISS-MODEL, and (C) Ramachandran plot analysis of 3D modeled structure validated by PROCHECK program. 


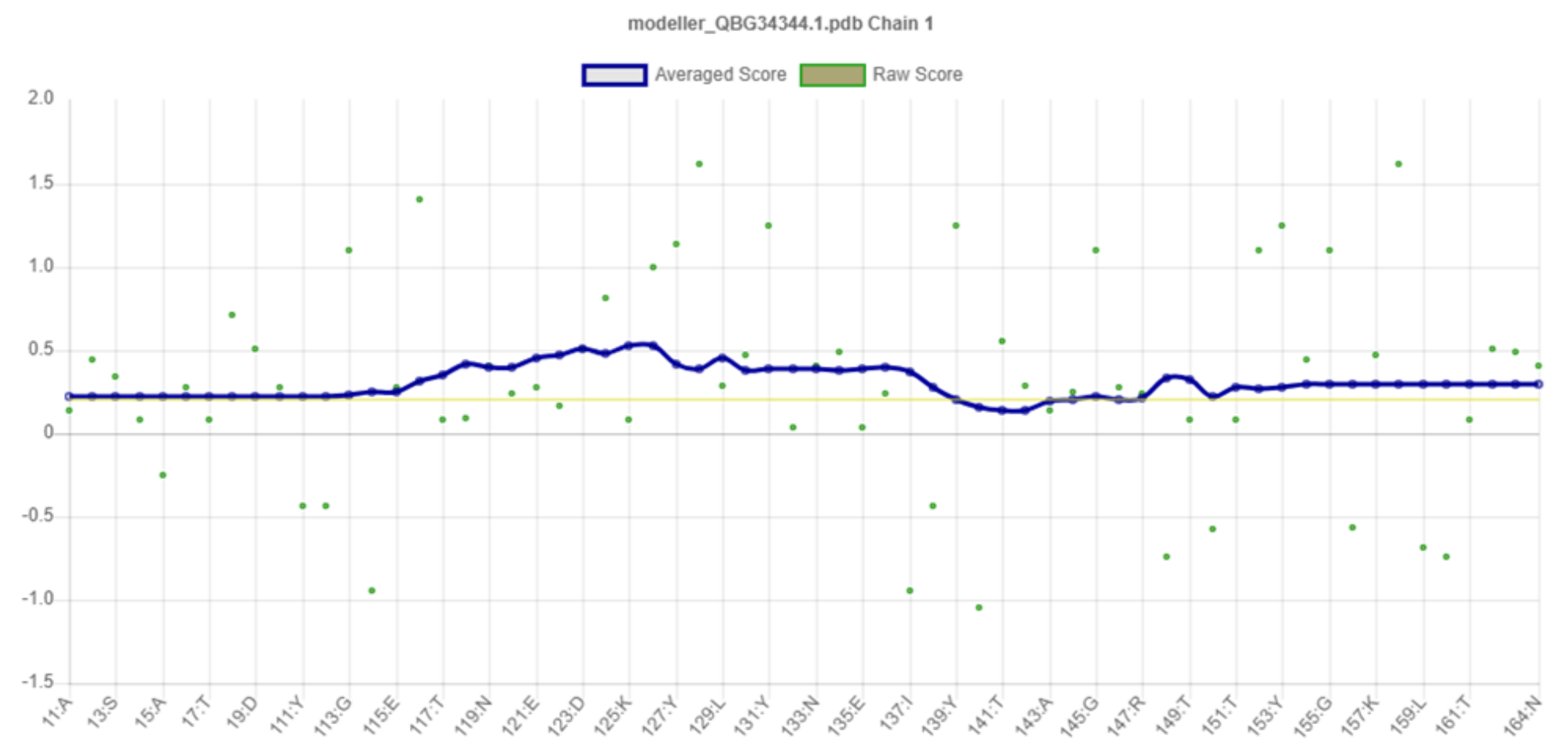

Figure 5

3D-structure validation by Verifiy3D.

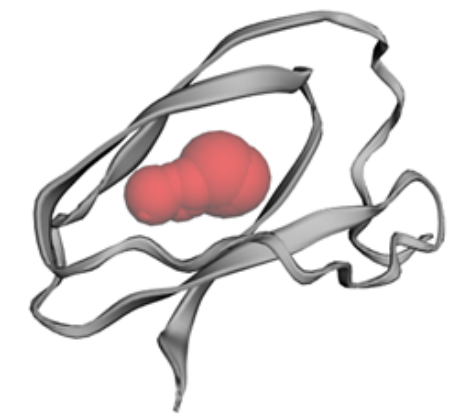

(A)
Chain X

A PSTAETFDEYYGIEFTNNRESDIK VYWLKYENAE

RI Y Y Y T L A Q GERVTQTGYPGNKWLVTDAN

\section{Figure 6}

Active site of the hypothetical protein, (A) Binding site of the hypothetical protein indicated by red region, and (B) Amino acids involved in the active site. 


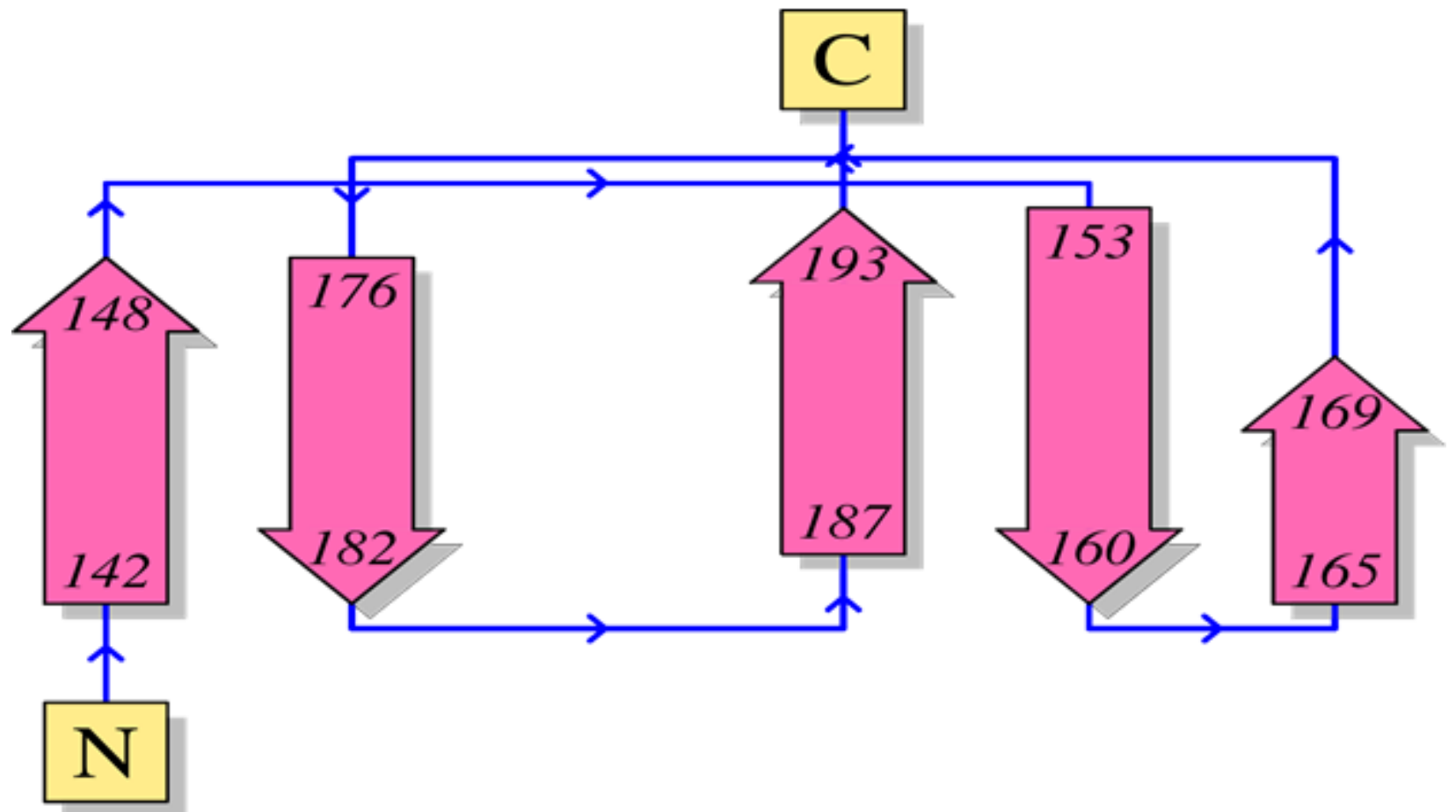

Figure 7

Topology of hypothetical protein

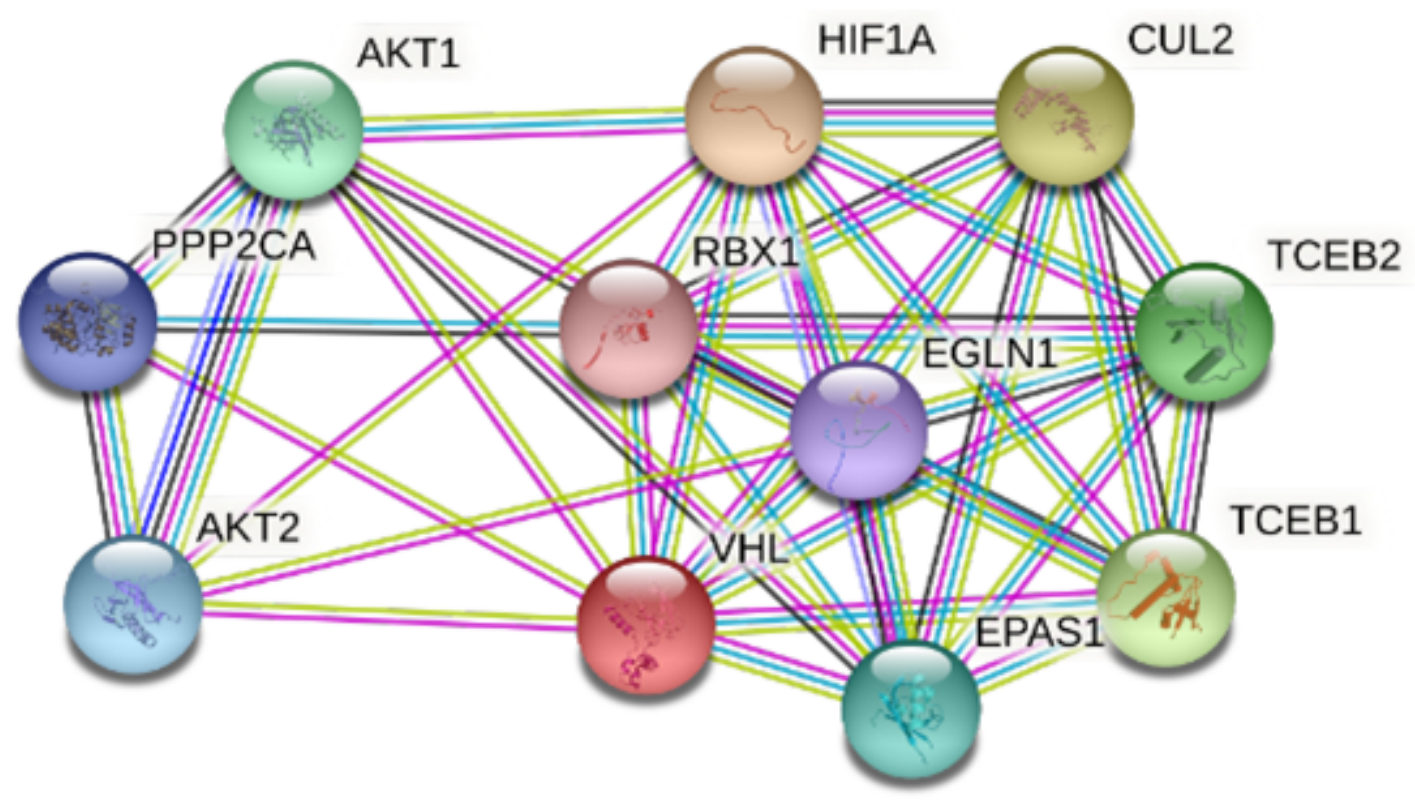

Figure 8

Protein-protein interaction network of the hypothetical VHL protein

\section{Supplementary Files}


This is a list of supplementary files associated with this preprint. Click to download.

- SupplementaryMaterialsnaturesubmission.docx 